\title{
Lung volume reduction surgery in hypercapnic patients: a single-center experience from China
}

\author{
Bin You", Yan Zhao", Shengcai Hou, Bin Hu, Hui Li \\ Department of Thoracic Surgery, Beijing Chaoyang Hospital, Capital Medical University, Beijing 100020, China \\ Contributions: (I) Conception and design: B You, Y Zhao; (II) Administrative support: H Li; (III) Provision of study materials and patients: S Hou, B \\ $\mathrm{Hu}, \mathrm{H} \mathrm{Li}$; (IV) Collection and assembly of data: B You; (V) Data analysis and interpretation: B You, Y Zhao; (VI) Manuscript writing: B You, Y Zhao; \\ (VII) Final approval of manuscript: All authors. \\ "These authors contributed equally to this work. \\ Correspondence to: Hui Li. Department of Thoracic Surgery, Beijing Chaoyang Hospital, Capital Medical University, Beijing 100020, China. \\ Email: Huilee@vip.sina.com.
}

\begin{abstract}
Background: Lung volume reduction surgery (LVRS) has shown early promise as a palliative therapy in severe emphysema, but with a controversy over its indications. The aim of this study was to evaluate whether patients with hypercapnia should be excluded from LVRS.

Methods: Total 15 cases of severe emphysema with the level of $\mathrm{PaCO}_{2}$ exceeding $50 \mathrm{mmHg}$ were retrospectively studied. Their basic characteristics, pulmonary function, preoperative and postoperative $\mathrm{PaCO}_{2}$ level as well as postoperative complications were calculated statistically.

Results: All of the 15 patients received video-assisted thoracoscopic LVRS and finally discharged uneventfully from hospital after the surgical procedures. Nine cases were supported by mechanical ventilation after surgery with the median duration of 44 hours. One of them was treated by extracorporeal membrane oxygenation (ECMO) both during surgery and the first 4 days after surgery. The result of blood gas analysis on 3 months after hospital discharge decreased than that before surgery $(60.07 \mathrm{vs} .55 .61 \mathrm{mmHg}$, $\mathrm{P}=0.076$ ), but without statistical significance.
\end{abstract}

Conclusions: The emphysematous patients with hypercapnia should not be excluded from the benefits of LVRS.

Keywords: Lung volume reduction surgery (LVRS); chronic obstructive pulmonary disease (COPD); hypercapnia; China

Submitted Nov 15, 2017. Accepted for publication May 29, 2018.

doi: $10.21037 /$ jtd.2018.05.195

View this article at: http://dx.doi.org/10.21037/jtd.2018.05.195

\section{Introduction}

Chronic obstructive pulmonary disease (COPD) is a chronic and progressive airway inflammatory disease which is characterized by irreversible airflow limitation with shortness of breath, poor exercise tolerance and impaired health status on the final stage (1-3). Since 2012, COPD has been the third leading cause of death in the world, with nearly 3.1 million deaths per year, second only to ischemic heart disease and stroke patients. In China, COPD causes the death of more than one million COPD patients every year, becoming the second highest in the health economic burden (4). The treatment is mainly based on internal medicine and long-term oxygen therapy. However, the effect of drug treatment alone is not satisfactory at the advanced stage and the overall survival is poor. It has been proved that lung volume reduction surgery (LVRS) may improve exercise capacity, quality of life, and increase longterm survival in selected patients with severe emphysema (5).

The randomized controlled study as the landmark NETT study provided valuable outcome information on 1,218 patients in 2003 . It clarified the indications 
Table 1 Demographic data and clinical results of the 15 cases

\begin{tabular}{|c|c|}
\hline Factors & Data \\
\hline Age [years] & $58.00 \pm 8.47[41-73]$ \\
\hline \multicolumn{2}{|l|}{ Gender } \\
\hline Male & 12 \\
\hline Female & 3 \\
\hline \multicolumn{2}{|l|}{ Smoking history } \\
\hline Yes & 9 \\
\hline No & 6 \\
\hline BMI & $20.74 \pm 2.10$ \\
\hline \multicolumn{2}{|l|}{ Surgical approach } \\
\hline VATS Uni-LVRS & 12 \\
\hline VATS Bi-LVRS & 3 \\
\hline \multicolumn{2}{|l|}{ Use of ventilator } \\
\hline Yes & $9^{*}$ \\
\hline No & 6 \\
\hline Ventilation time [hours] & Median 44 [17-336] \\
\hline Drainage time (day) & $10.2 \pm 4.8$ \\
\hline Mortality & 0 \\
\hline \multicolumn{2}{|l|}{ Postoperative complications } \\
\hline Yes & $9^{\#}$ \\
\hline No & 6 \\
\hline Hospitalization time (day) & $15.3 \pm 7.9$ \\
\hline
\end{tabular}

*, there were 7 cases of them undergoing invasive mechanical ventilation after palinesthesia; while the other 2 patients treated by non-invasive positive pressure ventilation during their recovering; " the complications after surgery included air leakage continuing over 7 days in 7 cases, 4 cases of pneumonia, 2 of atrial arrhythmia and 1 of acute cardiac insufficiency. BMI, body mass index; VATS, video-assisted thoracoscopic surgery; Uni-LVRS, unilateral-lung volume reduction surgery; Bi-LVRS, bilateral-lung volume reduction surgery.

and redefined the details of preoperative management. The point was that the patients with severe hypercapnia were excluded $\left(\mathrm{PaCO}_{2}>55 \mathrm{mmHg}\right)$ (6). Since then, the conclusions of NETT study have become a global guideline for patient selection and management; whereas, the dispute about whether hypercapnia was a relative contraindication of LVRS is still go on. In China, patients with severe emphysema and hypercapnia are common, many of whom have received surgical treatment and reaped the benefits thereof. Hence, stronger evidence is needed to confirm that preoperative hypercapnia is a justified exclusion criterion for LVRS.

\section{Methods}

\section{Participants}

From January 01 of 2012 to September 30 of 2017, 47 patients suffered from severe emphysema consecutively received LVRS in our medical center. Among them, 15 patients who suffered from severe heterogeneous emphysema accompanied with different levels of hypercapnia were filtered into this study and signed informed consent before taking part. The severe degree was generally defined by a blood gas carbon dioxide level over $50 \mathrm{mmHg}$. The clinical characteristics of these 15 cases are shown in Table 1.

All patients met the NETT inclusion and exclusion criteria (6): patients with a forced expiratory volume in one second (FEV1) that was $20 \%$ or less of the predicted value and either a homogeneous distribution of emphysema or a carbon monoxide diffusing capacity that was $20 \%$ or less of the predicted value were excluded from consideration. The CT scan showed severe upper lobe-predominant emphysema and most of these cases presented bulla formation. Pulmonary function tests of all patients were performed in the pulmonary function laboratory before surgery from 3 days to 1 month. Arterial blood gas analysis was carried out on the day before surgery and 3 months after surgery (Table 2). Cardiac ultrasonography was adopted to assess the circulatory function and exclude moderate or severe pulmonary arterial hypertension $(\mathrm{PAH})$.

This study was approved by the Institutional Research Ethics Committee of Beijing Chaoyang Hospital, Capital Medical University (ID: 2017-S-138). All the patients signed the informed consent before surgery.

\section{Surgery}

All of the 15 patients underwent video-assisted thoracoscopic LVRS, either unilaterally or bilaterally. The most severely portions of the lungs were identified by preoperative CT scans and ventilation perfusion scans. This preoperative information was combined with the anatomic findings at surgery for the determination of the site and 
Table 2 The results of preoperative pulmonary function tests and the data of postoperative arterial blood gas analysis

\begin{tabular}{lcc}
\hline Pulmonary function tests & $\bar{x} \pm \mathrm{s}^{*}$ & $t$ and P value \\
\hline Preoperative pulmonary function & $0.99 \pm 0.34$ & $42.0 \pm 8.9$ \\
FEV1 (L) & $104.4 \pm 16.7$ \\
FEV1\% (\%) & $157.5 \pm 21.4$ \\
TLC (\%) & $48.2 \pm 12.4$ \\
RV (\%) & $72.15 \pm 8.51$ \\
DLCO (\%) & $75.89 \pm 10.30$ \\
Preoperative $\mathrm{PaO}_{2}(\mathrm{mmHg})$ & $60.07 \pm 13.26$ \\
Postoperative $\mathrm{PaO}_{2}(\mathrm{mmHg})$ & $55.61 \pm 6.94$ & $t=-2.200 ; \mathrm{P}=0.045$ \\
Preoperative $\mathrm{PaCO}_{2}(\mathrm{mmHg})$ & & \\
Postoperative $\mathrm{PaCO}_{2}(\mathrm{mmHg})$ & &
\end{tabular}

*, values are mean \pm standard deviation. FEV1, forced expiratory volume in 1 second; FEV1\%, FEV1/FVC; FVC, forced vital capacity; TLC, total lung capacity; RV, residual volume; $\mathrm{DLCO}$, diffusing capacity of the lung for carbon monoxide; $\mathrm{PaCO}_{2}$, partial pressure of carbon dioxide; $\mathrm{PaO}_{2}$, partial pressure of oxygen.

extent of resection. The staple lines were buttressed with polytetrafluoroethylene to reduce postoperative air leaks. To drain sufficiently, 2 drainages were placed, which would be removed if there was no air leakage and with a drainage volume of $200 \mathrm{~mL}$ ( $24 \mathrm{~h}$ ) or less.

\section{Statistics}

The SPSS software package 19.0 for windows was used for statistical analysis. Continuous data was shown as mean \pm SD or as median and interquartile range (IQR). For the comparison of preoperative and postoperative $\mathrm{PaCO}_{2}$ paired sample $t$-test was used. $\mathrm{P}$ values less than 0.05 were considered as statistical significant.

\section{Results}

All 15 patients were discharged from hospital after successful surgical procedures. The blood gas analysis showed different levels of hypercapnia. The most frequent complication after surgery was air leakage continuing over 7 days and up to 20 days, which involved 7 cases of the total. The other postoperative complications included 4 cases of pneumonia, 2 of atrial arrhythmia and 1 of acute cardiac insufficiency. Under the sustaining chest drainage and antibiotic treatment, the patients suffering from postoperative complications were cured finally within their hospitalization.
After consciousness returned, based on the assessment by anesthetists, 7 patients needed continuing mechanical respiration as they could not preserve the basic oxygenation or carbon dioxide elimination by spontaneous respiration. One of the patients was supported by using of extracorporeal membrane oxygenation (ECMO) during the anesthetic management and the first 4 days after surgery. The endotracheal catheter of the rest 8 patients was removed from operating room immediately after consciousness returned. Two patients of them were treated by the non-invasive positive pressure ventilation accordingly after being transferred to the ward. Duration of mechanical ventilation is showed in the Table 1 .

The arterial blood gas analysis was reexamined 3 months after hospital discharge. The preoperative and postoperative data of the $\mathrm{PaCO}_{2}$ are shown in Table 2. The result indicates that postoperative hypercapnia did not change obviously compared with preoperative one, but the symptoms (cough, expectoration and dyspnea) did change.

\section{Discussion}

COPD is now a widely recognized disease with an increasing trend throughout the globe. A large number of patients with advanced disease have been seen to deteriorate quite rapidly in their course, or to be off control. A few of them received more radical approach like lung transplantation, despite the fact that proper medical 
therapy is the popular treatment for COPD. It is accepted that lung transplantation is the only way to reverse the course of COPD. Nevertheless, immune rejection and immunosuppression, as well as the lack of donors, limit the application of lung transplantation. It is demonstrated that LVRS can enhance the quality of life and exercise capacity through removing excessive and non-functional part of lung. Meanwhile, it becomes the bridge of lung transplantation. In China, thousands of patients with severe emphysema undergo LVRS per year; while the development of lung transplantation is still limited.

This study showed that the symptoms of 15 patients with preoperative hypercapnia had been improved after LVRS, and their result of blood gas analysis took a turn for the better. Furthermore, there was no increased morbidity or mortality associated with surgical procedure. It has been considered that hypercapnia is a high-risk factor for LVRS because it is classically regarded as a clinical marker of the end-stage emphysema. Hypercapnia had been once classified as a relative contraindication of LVRS for many years, although its relevance to abortive LVRS was far from clarified, according to previous studies. Even in the NETT trail, hypercapnic patients were excluded $\left(\mathrm{PaCO}_{2}>55 \mathrm{mmHg}\right)$. As a result, the majority of Chinese surgeons consistently refuse to perform LVRS on the emphysematous patients with hypercapnia. Our result demonstrated that patients with high $\mathrm{PCO}_{2}$ levels should not be excluded from the benefits of LVRS. The patients undergoing LVRS got improvement in their quality of life and decrease in $\mathrm{PaCO}_{2}$ (60.07 vs. $55.61 \mathrm{mmHg}$ ), though it was not statistical significant $(\mathrm{P}=0.076)$. Actually, it has been reported previously that the emphysematous patients complicated with hypercapnia were of benefit from LVRS, without significant increase in surgery-correlative mortality (7). Therefore, it is essential to find out whether hypercapnia is a contraindication for LVRS. More credible evidences like prospective randomized controlled trail are needed.

It is identified that many indicators should be evaluated prior to LVRS, such as pulmonary functional parameters, blood gas analysis, nutritional status, ventilation/perfusion distribution and so on. Previous studies have improved the evaluation of lung function indicators for LVRS, but not all patients tolerate the pulmonary function tests. Chest CT and blood gas analysis are relatively objective. According to our study, the distribution of emphysema was heterogeneous in different levels on the basis of highresolution computed tomography and using a visual scoring system (8). Compared with the level of $\mathrm{PaCO}_{2}$, the heterogeneity of emphysema or enormous bulla formation seems to be a more convincing indicator for LVRS. Among the 15 cases in this study, the patients with enormous bulla formation obtained short-term curative effects obviously. For instance, a huge bulla was found in a 48 -year-old male patient and occupied about two thirds of the volume of his left thorax by chest CT (Figure 1). Blood gas analysis showed that his preoperative $\mathrm{PaCO}_{2}$ level was up to $103 \mathrm{mmHg}$ even if the BiPAP assistant ventilation was used. The patient was extubated less than 24 hours after videoassisted LVRS; and then the level of $\mathrm{PaCO}_{2}$ decreased quickly to $57 \mathrm{mmHg}$ only with the nasal cannulas. It should be pointed out that the level of $\mathrm{PaCO}_{2}$ is not the only scale for preoperative assessment at least. Unfortunately, at present no reliable method can be used to quantify the heterogeneity of emphysema.

Besides the indications summarized by NETT and the same kinds of RCT researches, some characters of emphysema are valuable of surgical assessment. For instance, heterogeneity of the emphysema is an important factor which often influences our therapeutic strategy, although it is difficult to be quantified as an indicator. Within this cohort we are introduced, huge bulla were found in almost all cases that it means the extreme heterogeneity and the most appropriate target region. Another potential parameter to be considered is the course of the disease. A patient gotten obvious progressing within a short period seems more likely to be benefit from the LVRS in comparison to that with a long course of the disease. Unfortunately, it is unable to be quantified as well. Furthermore, a few symptoms often hint that LVRS may be helpful, such as the mediastinal excursion, hypertension of the thoracic cavity, relapsing pneumothorax, and so on. It is suggested that hypercapnia should not be so negative in presence of these symptoms according to our study.

Along with the science unceasing progress, more and more advanced technologies are applied to improve therapy and reduce patients' pain in medical area. ECMO is widely used in the treatment of patients with respiratory failure. Our affiliation reported a case of a patient who required LVRS because of emphysema. ECMO was required both during surgery and for the first 4 days after surgery. The patient presented himself as an emergency with an acute exacerbation of dyspnea. The preoperative blood gas analysis showed $\mathrm{pH} 7.257, \mathrm{pO}_{2} 75.1 \mathrm{mmHg}$, $\mathrm{pCO}_{2} 98.9 \mathrm{mmHg}$ and $\mathrm{SO}_{2} 92 \%$. After surgical treatment, the symptoms were relieved and $\mathrm{pCO}_{2}$ was down to 

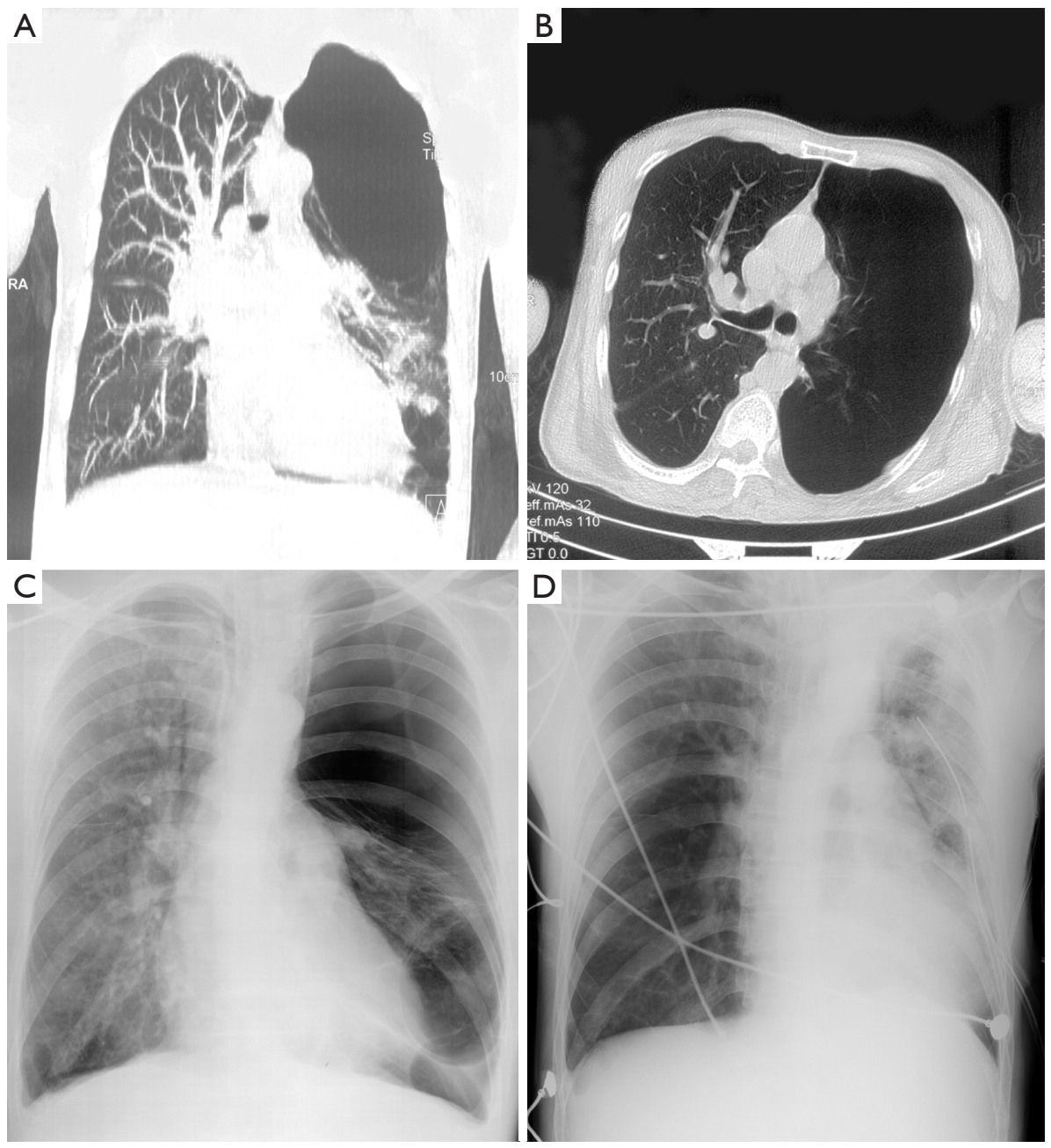

Figure $1 \mathrm{CT}$ scan and X-ray showed that the huge bulla was located in the upper lobe (A,B,C). For the first day after the surgery, chest radiography showed the remaining lung reflated well (D). CT, computed tomography.

60.6 mmHg (9). Therefore, patients with high $\mathrm{PCO}_{2}$ levels need not to be excluded from the benefits of LVRS.

The aim of classic internal medicine therapy is limited to eliminating inflammation, relieving bronchial spasm and improving ventilation. However, the clinical symptoms tended to aggravate repeatedly in short term. For these patients, LVRS had been affirmed by many doctors in the early effect. In recent years, many Chinese clinicians continue to deepen the study about LVRS, and some unique points of view have been summarized. Jiang et al. (10) summed up 43 postoperative cases after 5 years. They found that postoperative pulmonary function had the best curative effect in 1-2 years and then decreased year by year. This finding was similar to the study of Meyers (11). Zhao et al. (12) concluded after investigation that the lung function evaluated within 24 months after surgery was slightly lower than that in 12 months; whereas, the quality of life was relatively stable. Huang et al. (13) proposed that LVRS offered more benefits regarding survival, lung function, gas exchange, exercise capacity and quality of life than medical treatment, despite the higher mortality in initial three postoperative months.

\section{Conclusions}

In summary, there was a significant curative short-term effect by LVRS, although hypercapnia is considered to be one of the risk factors for LVRS. It is suggested that the heterogeneity of emphysema in CT scan is more important than the analysis of blood gas for prognosis assessment. 
Also it was believed that patients with hypercapnia should be considered for LVRS. This conclusion only represents short-term effect and forward efficacy needs to be supported by further research.

\section{Limitation}

Because the patients of this report lived in foreign ports far from our hospital, few of them accepted the post-operative following-up and the pulmonary function test. Therefore, the outcome of the post-operative pulmonary function was limited and unconvincing. Herein, the efficiency of LVRS was evaluated by improvement of subjective symptom rather than reliable laboratory examination. The prospective study based on sufficient evidences is looked forward and needed in the further.

\section{Acknowledgements}

None.

\section{Footnote}

Conflicts of Interest: The authors have no conflicts of interest to declare.

Ethical Statement: This study was approved by the Institutional Research Ethics Committee of Beijing Chaoyang Hospital, Capital Medical University (ID: 2017S-138). All the patients signed the informed consent before surgery.

\section{References}

1. Sardenberg RA, Younes RN, Deheizelin D. Lung volume reduction surgery: an overview. Rev Assoc Med Bras (1992) 2010;56:719-23.

2. Decramer M. Treatment of chronic respiratory failure: lung volume reduction surgery versus rehabilitation. Eur Respir J Suppl 2003;47:47s-56s.

3. Hillerdal G, Löfdahl CG, Ström K, et al. Comparison

Cite this article as: You B, Zhao Y, Hou S, Hu B, Li H. Lung volume reduction surgery in hypercapnic patients: a singlecenter experience from China. J Thorac Dis 2018;10(Suppl 23):S2698-S2703. doi: 10.21037/jtd.2018.05.195 of lung volume reduction surgery and physical training on health status and physiologic outcomes: a randomized controlled clinical trial. Chest 2005;128:3489-99.

4. Vogelmeier CF, Criner GJ, Martinez FJ, et al. Global Strategy for the Diagnosis, Management, and Prevention of Chronic Obstructive Lung Disease 2017 Report: GOLD Executive Summary. Arch Bronconeumol 2017;53:128-49.

5. Clark SJ, Zoumot Z, Bamsey O, et al. Surgical approaches for lung volume reduction in emphysema. Clin Med (Lond) 2014;14:122-7.

6. Fishman A, Martinez F, Naunheim K, et al. A randomized trial comparing lung-volume-reduction surgery with medical therapy for severe emphysema. $\mathrm{N}$ Engl J Med 2003;348:2059-73.

7. Ariyaratnam $\mathrm{P}$, Tcherveniakov $\mathrm{P}$, Milton R, et al. Is preoperative hypercapnia a justified exclusion criterion for lung volume reduction surgery? Interact Cardiovasc Thorac Surg 2017;24:273-9.

8. Fishman A, Fessler H, Martinez F, et al. Patients at high risk of death after lung-volume-reduction surgery. $\mathrm{N}$ Engl J Med 2001;345:1075-83.

9. Li X, He H, Sun B. Veno-venous extracorporeal membrane oxygenation support during lung volume reduction surgery for a severe respiratory failure patient with emphysema. J Thorac Dis 2016;8:E240-3.

10. Jiang GN, Ding JA. Functional results of lung volume reduction surgery in 43 patients with severe emphysema. Chin J Thorac Cardiovasc Surg 2002;18:287-9.

11. Meyers BF, Yusen RD, Guthrie TJ, et al. Results of lung volume reduction surgery in patients meeting a national emphysema treatment trial high-risk criterion. J Thorac Cardiovasc Surg 2004;127:829-35.

12. Zhao XD, Shi KH, et al. Changes of pulmonary function and quality of life in mid.term after lung volume reduction surgery. Chin J Thorac Cardiovasc Surg 2014;30:27-9.

13. Huang W, Wang WR, Deng B, et al. Several clinical interests regarding lung volume reduction surgery for severe emphysema: meta-analysis and systematic review of randomized controlled trials. J Cardiothorac Surg 2011;6:148. 